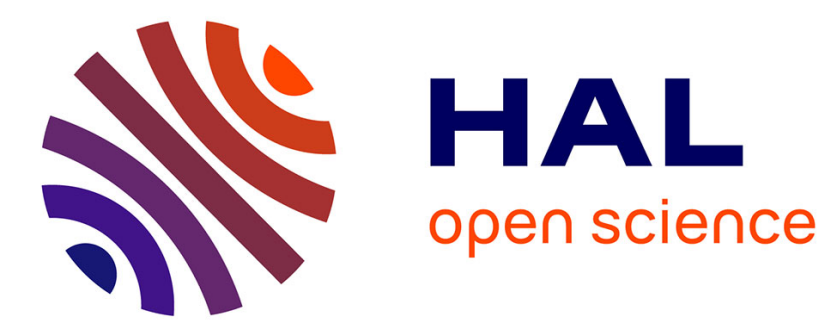

\title{
I know you can see me: Social attention influences bodily self-awareness
}

Nesrine Hazem, Nathalie George, Matias Baltazar, Laurence Conty

\section{To cite this version:}

Nesrine Hazem, Nathalie George, Matias Baltazar, Laurence Conty. I know you can see me: Social attention influences bodily self-awareness. Biological Psychology, 2017, 124, pp.21 - 29. 10.1016/j.biopsycho.2017.01.007 . hal-01447905

\section{HAL Id: hal-01447905 https://hal.sorbonne-universite.fr/hal-01447905}

Submitted on 27 Jan 2017

HAL is a multi-disciplinary open access archive for the deposit and dissemination of scientific research documents, whether they are published or not. The documents may come from teaching and research institutions in France or abroad, or from public or private research centers.
L'archive ouverte pluridisciplinaire $\mathbf{H A L}$, est destinée au dépôt et à la diffusion de documents scientifiques de niveau recherche, publiés ou non, émanant des établissements d'enseignement et de recherche français ou étrangers, des laboratoires publics ou privés. 


\section{KNOW YOU CAN SEE ME: SOCIAL ATTENTION INFLUENCES BODILY SELF-AWARENESS}

Nesrine HAZEM1,2,3*, Nathalie GEORGE2,3,4,5,6, Matias BALTAZAR ${ }^{1}$, Laurence CONTY1

1 Laboratory of Human and Artificial Cognition (CHart-UPON EA4004), Paris 10 University, Nanterre, France;

2 Institut du Cerveau et de la Moelle épinière (ICM), Social and Affective Neuroscience Laboratory and Centre MEG-EEG, Paris, France;

3 Sorbonne Universités, UPMC Univ Paris 06, UMR_S 1127, Paris, France;

${ }^{4}$ CNRS, UMR 7225, Paris, France;

5 Inserm, U 1127, Paris, France

${ }^{6}$ ENS, Centre MEG-EEG, Paris, France

Running Title: Social attention influences bodily self-awareness

Abstract: 149 words

Main text: 6345 words

Number of Tables: 1

Number of Figures: 2

* Corresponding author at: Social and Affective Neuroscience Laboratory, Institut du Cerveau et de la Moelle épinière (ICM), 47 bd de l'hôpital, 75013 Paris cedex 13. Tel.: +33157274310

E-mail address: Ness.hazem@gmail.com 


\section{HIGHLIGHTS}

- Direct gaze was shown to increase bodily self-awareness.

- We tested if the belief to be watched by another triggers similar effect.

- Subjects' accuracy in judging their body emotional arousal state was measured.

- We show that the belief to be watched lead to increased interoceptive accuracy.

- Basic mentalizing may be a key process in the self-awareness effect of direct gaze.

\section{ABSTRACT}

It has recently been demonstrated that eye contact influences bodily self-awareness. Here, we investigated if the belief of being the target of another person's attention may also induce such influence. We created videos of an individual wearing two different pairs of sunglasses. We manipulated the participants to believe that they were in on-line connection with the individual and that one of the pairs of sunglasses was obstructed so that the individual could not see them through it. We demonstrated that the perception of an individual wearing see-through sunglasses, as compared to obstructed sunglasses or a low-level baseline condition, led to a greater correlation between the participants' rating of the intensity of their bodily reactions and their skin conductance response to emotional pictures. This shows that the belief to be watched by another social agent increases bodily self-awareness and further suggests that such belief is embedded in direct gaze perception.

Keywords: Eye contact, mental state, interoception, bodily self-awareness, skin conductance response 


\section{Introduction}

Perceiving another's gaze directed at the self (i.e. a 'direct gaze') has a powerful impact on human cognition and behaviour and direct gaze has been proposed to be processed by a specific brain network (Senju \& Johnson, 2009). Besides capturing attention (Conty, Tijus, Hugueville, Coelho, \& George, 2006; Senju \& Hasegawa, 2005; Senju, Hasegawa, \& Tojo, 2005), direct gaze perception facilitates memory for faces (Mason, Hood, \& Macrae, 2004; Vuilleumier, George, Lister, Armony, \& Driver, 2005) and discourses (Fullwood \& Doherty-Sneddon, 2006), it influences the perception that the beholder has of the gazing individual (Napieralski, Brooks, \& Droney, 1995), and it favours affiliative behaviours (Nettle et al., 2013; Wang, Newport, \& Hamilton, 2011). Recently, another direct gaze effect on human cognition has attracted researchers' interest: direct gaze perception has been shown to increase self-awareness (Baltazar et al., 2014; Pönkänen, Peltola, \& Hietanen, 2011).

Pönkänen and colleagues (2011) reported that, in live interaction, subjective ratings of "public self-awareness", which reflects how much one is concerned toward aspects of the self that are external and observable by others (Govern \& Marsch, 2001), were higher when seen faces displayed direct compared to averted gaze. Furthermore, we recently showed that the perception of direct gaze - as compared to that of averted gaze or of a mere fixation cross - also increased a private aspect of self-awareness, that is, bodily self-awareness (Baltazar et al., 2014). In this experiment, bodily self-awareness was measured in the form of the correlation between the participants' ratings of the intensity of their bodily reactions in response to emotional pictures and their skin conductance response (SCR) to these pictures, which is associated with autonomic sympathetic activation and reflects bodily arousal (Mendes, 2009). Therefore, direct 
gaze perception induces greater sensitivity not only to aspects of the self readily perceived by others but also to private aspects of self-awareness, which are related to internal aspects of the self, not directly accessible to others' gaze (Auzoult, 2013), such as bodily self-awareness, i.e. the awareness of the afferent information that arises from within the body (Cameron, 2001).

The idea that the perception of direct gaze may increase self-awareness is not new (see Argyle, 1975; Reddy, 2003). It has been proposed that this direct gaze effect emerges early during development and may play a fundamental role in the acquisition of conceptual representations of the self (Reddy, 2003). Yet, this effect still remains to be fully understood. In particular, the role played by the basic mentalistic belief of being the target of another person's attention (i.e. the belief to be watched), which is tightly associated with direct gaze perception, is unknown. Here, we aimed at testing whether such a belief may increase bodily self-awareness just as direct gaze does.

Recent studies have shown that mental state attribution plays an important role in gaze perception. Namely, the neural coding and the behavioural attention orienting effect of rightward and leftward averted gazes was reduced when participants believed that the stimulus faces they saw were blinded (Teufel et al., 2009; Teufel, Alexis, Clayton, \& Davis, 2010). Moreover, believing that a robotic face reflected in live the intentional gaze movements of an experimenter influenced the attention orienting effect of averted gaze, as measured both at the behavioural level and at the level of attentional modulation of early visual electroencephalographic evoked responses (Wiese, Wykowska, Zwickel, \& Müller, 2012; Wykowska, Wiese, Prosser, \& Müller, 2014). Yet, the role of mental state attribution in the effects of direct gaze remains to be investigated. 
Only one previous study examined this question. Myllyneva and Hietanen (2015b) have recently shown greater public self-awareness in participants believing that a person displaying direct gaze could see them, as compared to when they believed that this person could not see them. This result brought the first empirical evidence that the 'belief to be watched by another person' attached to direct gaze is essential to the influence of direct gaze on self-awareness. However, public self-awareness concerns external and observable aspects of the self that are directly relevant in a social context; it is the awareness of how we appear to others, which emerges especially in situations where people are at the centre of others' attention (Govern \& Marsch, 2001). It is thus possible that the public dimension of self-awareness may be especially sensitive to the belief to be watched. Here, we investigated whether this belief can influence a private dimension of self-awareness, namely bodily awareness.

For this purpose, we amended the paradigm developed by Baltazar and colleagues (2014), introducing a deception procedure inspired by Teufel and colleagues (2009). We showed videos of an individual facing the participant and wearing either a red or a blue pair of mirrored sunglasses, so that the eyes of the seen individual were not visible. The participants were led to believe that they were in on-line connection with the individual, and that one of the pair of sunglasses was obstructed so that the individual could not see through it, by contrast to the other, see-through, pair of sunglasses. We thus created two conditions contrasted in terms of the associated belief to be watched by the other person or not, while maintaining identical low level visual properties of the stimuli. As mentioned above, previous studies have shown that the belief to be in live connection with another individual influences markedly the neural response to and the behavioural attention orienting effect of averted gaze (Teufel et al., 2013; Wiese et al., 2012). For this 
reason, we introduced a post-experiment debriefing interview, which allowed us to check if the participant had actually believed to be in online connection with another individual and to split the participants in two groups as a function of their belief in the deception procedure.

The rest of the procedure was analogous to Baltazar and colleagues (2014). The individual's videos were shown as context stimuli preceding the presentation of emotional pictures. We also introduced a low-level control condition, in which the picture of a fixation cross was displayed as context stimulus. Our objective was to investigate the influence of the context video preceding each emotional picture on participants' behaviour. We asked the participants to rate the intensity of their bodily reactions in response to the emotional pictures and we recorded concomitantly the participants' physiological activity during the perception of the emotional pictures in the form of the skin conductance response (SCR). SCR reflects sympathetic autonomic nervous system activity and has been shown to be a good indicator of felt arousal (Bradley, Codispoti, Cuthbert, \& Lang, 2001; Lang, Greenwald, Bradley, \& Hamm, 1993). We computed the correlation between the SCR magnitude and the participant's ratings of the intensity of their bodily reaction on a trial by trial basis, in each type of context, to measure interoceptive accuracy as an index of bodily self-awareness (Baltazar et al., 2014). If the self-reports fit the physiological data, the participants may be considered to be more accurately aware of their bodily states (Silvia \& Gendolla, 2001). We expected to find greater correlation between SCR magnitude and participants' ratings when participants believed to be watched by the individual as compared to the other conditions.

\section{Materials and Methods}


Materials and methods were similar to those of Baltazar et al. (2014), except that the context stimuli were constituted by videos of an individual wearing sunglasses and a procedure of deception was added in order to make the participants believe that they were in online interaction with this individual.

\subsection{Participants}

Thirty-five adults (mean age $=24$ years, $S D=3.4 ; 14$ men) participated in the experiment. All participants had normal or corrected-to-normal vision and no neurological or psychiatric history. All were right-handed, French speakers, and naïve to the aim of the experiment. Informed written consent was obtained from each participant, in accordance with the Declaration of Helsinki. Each participant received a payment of 20 Euros.

\subsection{Stimuli}

Emotional stimuli. The same forty-eight emotional pictures $(24$ positive and 24 negative) as in Baltazar et al. (2014) were selected from the International Affective Picture Systems (IAPS; Lang, Bradley, \& Cuthbert, 2008) to induce emotional experience in our participants. These pictures were then selected according to three criteria: (i) The picture should not depict eye contact or frontal faces. (ii) Each picture should be consistently judged either positive or negative in an independent pretest that we realised on 28 participants (for the selected emotional pictures more than $75 \%$ of the participants agreed on the valence category provided by Lang et al., 2008). (iii) The final sample of 48 selected pictures should have a robust continuous distribution of arousal values from moderately to highly emotional (according to the values gathered in the pretest and those reported by Lang et al., 2008). The selected emotional pictures were 
then further divided in four sets of 12 stimuli: low positive, high positive, low negative, and high negative.

Context stimuli. As described in details in the Supplementary Material, sixty-four videos of $1.5 \mathrm{~s}$ duration featuring a man in 32 videos, and a female in the other 32 videos were created to generate the 'Observed' and 'Not-observed' contexts. The featured individual had a neutral expression and wore black sunglasses with a mirror effect to ensure that his/her eyes were not visible. The frame of the sunglasses was red in half of the videos, and blue in the other half, for both the male and the female individuals.

For the purpose of the deception procedure (see below), two additional short videos of the two selected individuals were prepared where they did not wear any sunglasses. In the first video, the individual was smiling and waving his/her hand in a greeting gesture. In the second video, the individual made a thumbs-up gesture.

\subsection{Experimental protocol}

All participants completed an introduction/deception phase, followed by a reinforcement phase $(10 \mathrm{~min})$, the main experiment $(30 \mathrm{~min})$, a post-test phase $(5 \mathrm{~min})$, and a debriefing $(10 \mathrm{~min})$. The participants were seated at a distance of $70 \mathrm{~cm}$ from the computer screen. The stimuli were presented in the centre of a 22 -inches screen with a resolution of 1280 x 1024 pixels. The models' faces covered 12 degrees of visual angle horizontally and 18 degrees vertically, the fixation cross covered 3-by-3 degrees and the emotional pictures 39-by-24 degrees.

Each participant was exposed to the videos of a single stimulus individual (the male individual for half the participants, and the female individual for the other half) and saw 
once every video of that individual during the main experiment ( $\mathrm{n}=32$ videos, 16 with red / 16 with blue sunglasses).

Deception phase. After having welcomed the participant, the experimenter explained to him/her that another individual would be interacting with him/her through a webcam during the experiment. This individual was explicitly named Alexis for the participants confronted with the male individual and Nathalie for the participants confronted to the female individual. Alexis (or Nathalie) was introduced as someone especially trained for the necessities of the experiment and located during all the experiment in an adjacent room. The experimenter explained to the participant that during the experiment, Alexis (or Nathalie) would wear one of two pairs of sunglasses that had either a red or a blue rim, one pair being obstructed and the other being see-through. Then, the experimenter handed the two pairs of sunglasses to the participant. The participant was invited to try on the two pairs of sunglasses, in order to experience by him-/her-self that the wearer could see through one pair and not through the other pair (for half the participants, it was the red pair that was obstructed, and the blue pair that was see-through; this was reversed for the other half of the participants). The experimenter explained to the participant that when the video connection would be established with Alexis (or Nathalie), his/her own image would also be online broadcasted to Alexis (or Nathalie). The experimenter then repeated that, as a function of which pair of sunglasses Alexis (or Nathalie) would wear, he (or she) would either be able to see the participant or not.

Reinforcement phase. A training was first performed to strengthen the association between the sunglasses rim colour and the belief of the participants. In each trial, the photograph of an individual (who was neither Alexis nor Nathalie) wearing the red or the blue sunglasses was presented to the participant. This photograph was extracted 
from the videos of unselected individuals (see Supplementary Material), and incrusted on a black background to emphasize its difference with the videos of Alexis and Nathalie. On each trial, the participant had to indicate if the individual could see him/her or not by a two-choice button press and a feedback indicated whether he/she had given the correct answer. There were thirty-two initial trials and the sequence was programmed to restart until the participant reached a minimum score of $90 \%$ of correct answers. However, all participants reached this criterion within a single sequence of training.

To reinforce the deception procedure, after the training phase and before the start of the actual experiment, the experimenter left the room for a few minutes pretending to go for notifying Alexis (or Nathalie) that the experiment was about to start. Thereafter, the experimenter came back and pretended to put the video connection on. The participant then saw a video of $3.5 \mathrm{~s}$ showing Alexis (or Nathalie) smiling and greeting with the hand, without any sunglasses on. The participant was invited to greet Alexis (or Nathalie) in return. After giving the instructions of the experience itself (see below), a live connection of $3 \mathrm{~s}$ with Alexis (or Nathalie) was again simulated, on the pretext of telling Alexis (or Nathalie) that the experiment was starting. In this video, Alexis (or Nathalie) made a thumbs-up gesture in answer to the experimenter's notice. After this last manipulation, the experimenter launched the main experimental task and left the room.

Main experiment. Each trial was initiated by the presentation of a context stimulus for $1.5 \mathrm{~s}$. This context stimulus was a video of Alexis (or Nathalie) wearing the see-through sunglasses (Observed condition), a video of Alexis (or Nathalie) wearing the obstructed sunglasses (Not-observed condition), or a fixation cross (Cross condition). We used 16 trials per context condition (for a total of 48 trials). The order of the conditions was 
pseudo-randomized so that any given experimental condition was not repeated more than three times in a row.

Immediately after the context video ended, an emotional picture was presented for $6 \mathrm{~s}$ (see Fig. 1). Then, a continuous vertical scale ranging from 0 to 100 was displayed until the participant provided his/her response. The participants were instructed to focus on the internal bodily changes that the emotional picture caused in them during its presentation and to evaluate on this basis the intensity of their emotional reaction from 0 (not at all intense) to 100 (very intense) by moving a vertical cursor along the scale. It was specified that the bottom of the scale corresponded to have felt completely relaxed, quiet, calm, and without any particular bodily change induced by the picture, whereas the top of the scale corresponded to have felt very stimulated, excited or nervous, with intense bodily reaction to the picture. In addition, for a quarter of the trials, a new screen appeared after the participant's response, displaying the words "Observé", "Pas Observé", and "Croix" (Observed, Not-observed, and Cross) one alongside the other; the participant had then to indicate which type of context stimulus had been presented before the emotional picture. This constituted a secondary recall task to ensure that participants paid attention to the context stimuli. Between trials, the screen remained black for a duration varying randomly between 12 and $17 \mathrm{~s}$ in order to allow skin conductance to return to baseline level. For each participant, the association between the context video and the emotional stimuli was randomly assigned by E-prime 2.0 software (Psychology Software Tools Inc., Pittsburgh) with the constraint that every emotional picture $(n=48)$ was seen once during the experiment and that each category of emotional picture (High Positive/Low Positive/High Negative/Low Negative) was seen in equal proportion in each context condition (Observed/Not-observed/Cross). 
Post-test phase. After the experiment, the participant completed a post-test aimed at ensuring that the association between the sunglasses rim colour and the participants' belief had remained stable. The post-test was similar to the training, except that the participant had no feedback on his/her answers. The individuals seen in the post-test were different from the individuals seen during the training.

Debriefing. At the end of the experiment, a debriefing with standardized questions was conducted by the experimenter to determine whether the participant believed in the deception manipulation. The participant was asked to rate from 0 to 10 whether he/she believed to have been in online connection with another person (with 0 corresponding to "I did not at all believed to be in online connection with another person", and 10 to "I totally believed I was in online connection with another person"). This was used to categorize participants as Deceived or Not-deceived. The participants scoring beyond 5 were affected to the Deceived group and the ones scoring below or equal to 5 were affected to the Not-deceived group. In this study, 19 out 35 participants reported to have believed in the deception manipulation, with scores comprised between 6 and $10(M=$ 9.12, $\mathrm{SD}=1.41$ ). In contrast, the remaining 16 participants ( 7 females) did not believe in the deception manipulation; these participants had scores between 0 and $2(M=1.21$, $S D=0.58)$ and reported to be persuaded or strongly suspicious about the fact that the videos were pre-recorded.

\subsection{Physiological recordings and analysis}


Physiological responses were recorded using the acquisition system ADInstruments(C) (ML870/ Powerlab 8/30).

Skin conductance response (SCR). Two $\mathrm{Ag}-\mathrm{AgCl}$ electrodes filled with isotonic $\mathrm{NaCl}$ unibase electrolyte were attached to the palmar surface of the middle phalanges of the index and middle fingers of the non-dominant hand. The raw SCR signals were recorded at a sampling rate of $2 \mathrm{kHz}$, amplified and low-pass filtered online at $10 \mathrm{~Hz}$. Then, the SCR was offline subsampled at $2 \mathrm{~Hz}$. Trials containing artefacts or noisy baseline (i.e. mean of activity during the second preceding the video onset) were manually rejected (less than $9 \%$ of the trials). The SCR in response to the emotional picture was defined as the maximum change from the baseline level occurring between 1 and $6 \mathrm{~s}$ after the emotional picture onset. The SCR magnitudes were then log-transformed $[\log (\mu \mathrm{S}+1)]$ to normalize the data (Bradley et al., 2001).

\section{Correlations between SCR and subjective ratings of emotional response intensity.} We computed the correlation (Pearson's $r$ coefficient) between the SCR evoked by the emotional pictures and the ratings provided by the participants, in each condition (Observed/Not-observed/Cross) separately and for each participant. Then, we performed Fisher's r-to-z transformation in order to normalize the correlation values (Howell, 2012). We screened the Fisher's z scores for extreme values. Four participants (2 in the Deceived group, 2 in the Not-deceived group) had outlier values (Fisher's $\mathrm{z}$ scores differing by more than two standard deviations from the group mean in one or more experimental conditions); they were excluded from all subsequent analyses.

\subsection{Statistical analyses}

\subsubsection{Statistical analysis of the SCR-rating correlation data}


A repeated-measures ANOVA with Context (Observed/Not-observed/Cross) as withinsubject factor and Group (Deceived/Not-deceived) as between-subject factor was run on the Fisher's z scores (i.e. the normalized correlations between SCR and ratings during the main experiment).

For comparisons with two degrees of freedom, we used the Greenhouse-Geisser correction to correct for deviations from the assumption of sphericity (the $\varepsilon$ correction factor and the corrected $P$ or $P_{\text {corr }}$ are then reported). Effect sizes $\left(\eta^{2}\right)$ are reported together with $\mathrm{F}$ and $\mathrm{p}$ values for the main effects and interactions. Planned comparisons were further performed when simple main effects and/or interaction effects were observed.

\subsubsection{Control analyses}

Training phase and post-test phase. A repeated-measures ANOVA with Context (Observed/Not-observed) and Measurement occasion (Training phase/Post-test phase) as within-subject factors and Group (Deceived/Not-deceived) as between-subject factor was run on the reaction times (RT) and the percentages of correct answers (\%CR) obtained during those phases.

Secondary recall task. Repeated-measures ANOVAs with Context (Observed/Notobserved/Cross) as within-subject factor and Group (Deceived/Not-deceived) as between-subject factor were run separately on the RT and the \%CR obtained in the secondary recall task.

Main effects of context on arousal and ratings. As being observed by another individual has been associated with an increase in arousal (Helminen, Kaasinen, \& Hietanen, 2011; Nichols \& Champness, 1971), we conducted control analyses to check if 
the context stimulus (Observed/Not-observed/Cross) per se induced specific physiological or emotional responses during the task, which might partly account for our results. For this purpose, repeated-measures ANOVAs with Context (Observed/Notobserved/Cross) as within-subject factor and Group (Deceived/Not-deceived) as between-subject factor were carried out separately on SCR and on subjective ratings.

\section{Results}

\subsection{Correlation between SCR and ratings}

The ANOVA performed on the correlations between SCR and ratings did not reveal any significant main effect of Group $\left(F_{1,29}<1\right)$, nor of Context $\left(F_{2,58}<1\right)$ but a significant interaction between Context and Group $\left(F_{2,58}=3.71, \varepsilon=.96, P_{\text {corr }}=.032 ; \eta^{2}=.11\right)$. Context affected performances in the Deceived group only $\left(F_{2,32}=5.93, \varepsilon=.93, P_{\text {corr }}=\right.$ $.008 ; \eta^{2}=.27$; see Fig.2). In this group, the Observed context condition induced greater value of SCR-rating correlation (95\% Confidence interval $(\mathrm{CI})=0.12$ to 0.36$)$ than the Not-observed $\left(95 \% \mathrm{CI}=-0.13\right.$ to $\left.0.14 ; t_{1,16}=2.90, P=.010\right)$ and the Cross conditions $\left(95 \% \mathrm{CI}=-0.19\right.$ to $\left.0.13 ; t_{1,16}=2.81, P=.012\right)$ did. The Not-observed and Cross context conditions did not differ from one another $\left(t_{1,16}=-0.44, P=.663\right)$. There was not any effect of the context conditions in the Not-deceived group (95\% Clobserved $=-0.12$ to 0.07 ; 95\% $\mathrm{CI}_{\text {Not-observed }}=-0.16$ to $0.21 ; 95 \% \mathrm{CI}_{\text {Cross }}=-0.13$ to $0.33 ; F_{2,26}<1$ and all ts between conditions taken 2-by-2 <1). Furthermore, the interaction between Context and Group also reflected that the SCR-rating correlation was different between the Deceived and the Not-deceived group in the Observed context condition only $\left(t_{1,29}=3.62, P=.001\right)$. In contrast, this difference was not significant in the Not-observed and the Cross conditions (both $t_{1,29}<1$ ). 


\subsection{Control analyses}

Training phase and post-test phase. We checked the performance obtained by the participants during the training and the post-test, in order to ensure that they had welllearned the association between the sunglasses rim colour and the Observed/Notobserved conditions. The mean \%CR was at ceiling during training $(M=98.8 \%, S D=$ 2.7), with a mean RT of $992 \mathrm{~ms}(S D=219 \mathrm{~ms})$. This showed that the participants learned easily the association between the colour of the sunglasses rim and the capacity of the wearer to see. Similar performance was obtained in the post-test phase, with a mean \%CR of $99.3 \%(S D=2.3)$ and mean RT of $837 \mathrm{~ms}(S D=158 \mathrm{~ms})$, showing that the learnt association was retained throughout the experiment. The ANOVA run on these variables did not reveal any main effect or interaction.

Secondary recall task. The mean percentage of correct responses (\%CR) in the secondary memory task (performed over a quarter of the trials) was excellent $(M=$ $91.2 \%, S D=14.5$ ). This result ensured that the participants paid attention to the context stimuli during the main experiment. The mean response time (RT) was $2.1 \mathrm{~s}(S D=0.7 \mathrm{~s})$. The ANOVAs performed on \%CR and RT did not reveal any significant effect or interaction. Thus, the performance in the secondary memory task did not vary as a function of the context conditions or the groups. In particular, the Observed condition did not induce any enhancement of performance, either globally or in the Deceived group only.

Main effects of context on arousal and ratings. SCR was not modulated by the Context $\left(F_{2,58}<1\right)$. In other terms, the Observed condition did not elicit a higher arousal than the 
other context conditions did during our experiment. There was a main effect of Group on SCR $\left(F_{1,29}=4.26, P=.048 ; \eta^{2}=.13\right)$. The participants of the Deceived group showed higher SCR $(M=0.054, S D=0.064)$ than the participants of the Not-deceived group $(M=$ $0.020, \mathrm{SD}=0.024)$. The ANOVA on the subjective ratings did not reveal any effect of the Context $\left(F_{2,58}<1\right)$, nor of the Group $\left(F_{1,29}=2.37, P=.135\right)$ and there was not any interaction between these factors $\left(F_{2,58}=1.50, P=.232\right)$.

\section{Discussion}

The aim of this study was to determine whether the belief to be watched may enhance bodily self-awareness. Following a previously established procedure (Baltazar et al., 2014), we used the correlation between SCR magnitude and participant's rating of the intensity of their emotional bodily reaction to measure interoceptive accuracy as an index of bodily self-awareness. Our results showed that the perception of an individual wearing see-through sunglasses - who could therefore see the participant - as compared to the perception of an individual with obstructed sunglasses or to the perception of a mere fixation cross, led to a more accurate rating of the intensity of bodily reactions induced by emotional pictures, only in participants who believed to be in live connection with the individual. Consistently with our hypothesis, the belief to be watched by another person was thus associated with an increase of the participant's bodily self-awareness. This effect was neither attributable to a main effect of arousal nor to some general modulations of the participants' performance.

Our finding brings the first empirical evidence that the belief to be watched influences not only public self-awareness but also a private dimension of self-awareness. Myllyneva and Hietanen (2015b) showed greater public self-awareness in participants who believed that a person displaying direct gaze could see them, compared to when they 
believed that he/she could not. In this study, the authors did not find any significant effect of the belief to be watched on private self-awareness as measured by a self-rated questionnaire (Govern \& Marsch, 2001). However, it has been pointed out that selfreports may not be a reliable source of information regarding judgments about selfknowledge. For instance, such reports have been pointed out to be particularly affected by motivational concerns (Jones, 1990). It was therefore recommended to compare selfreports with an objective physiological variable in order to obtain a valid measure of bodily self-awareness (Silvia \& Gendolla, 2001). This was the approach adopted in the present study and it allowed us to bring novel insight into the self-related processes engaged during interpersonal contact.

There is inconsistency in the literature on how bodily self-awareness, also commonly called interoceptive awareness, is defined and quantified (Garfinkel, Seth, Barrett, Suzuki, \& Critchley, 2015). Interoceptive awareness classically refers to the representation of afferent bodily physiological sensations (Craig, 2003; Critchley et al., 2004), but it has recently been suggested that interoceptive processes are multiple and include sensitivity to internal bodily changes, accuracy in reporting those changes, as well as meta-cognitive awareness of interoceptive accuracy (Chentsova-Dutton \& Dzokoto, 2014; Farb et al., 2015; Garfinkel et al., 2015). As a consequence, the paradigms used to assess bodily self-awareness vary among studies. Here, we relied on the definition of bodily self-awareness as the adaptive capacity to detect and perceive body physiological signals in the context of the current activities (Craig, 2008; Damasio \& Carvalho, 2013). We asked our participants to rate the intensity of their bodily reactions in response to emotional pictures. Also worthy of note, participants were required to rate the intensity of their internal bodily reactions without focusing on a particular physiological cue (e.g. heart rate, respiration, or skin sweating). It is thus likely that we 
collected the participants' ratings of their general, bodily arousal state, which is reliably reflected by the SCR magnitude (Mendes, 2009). We then computed the across-trial correlation between this rating and the participant's physiological response (SCR), taking interoceptive accuracy as a proxy of bodily self-awareness. This approach was previously shown to be fruitful in revealing the effect of gaze contact on self-awareness (Baltazar et al., 2014). We extend it here to the belief to be watched.

Previous authors have suggested that such increase in bodily self-awareness might be mediated by a main effect of arousal or by some general modulation of performance (Silvia \& Gendolla, 2001), which might be related to an "audience effect", i.e. the social presence of another person (Zajonc, 1965). In order to test this hypothesis, we first ran several control analyses on the magnitude of SCR and subjective ratings taken separately. There was not any significant effect of context stimulus (Observed/Notobserved/Cross) or any interaction between context stimulus and group (Deceived/Not deceived), either on the participant's ratings or on the participant's SCR magnitude per se. In addition, the performance at the secondary memory task present in a quarter of the trials did not vary for the different context stimuli. These results converge with the findings of our previous study (Baltazar et al., 2014) and allow us to rule out that the effect of the belief to be watched on bodily self-awareness was mediated by general modulations in arousal or in performance. This suggests that social presence or audience effects cannot account for our finding. By ruling out such modulations, the present results support the view that self-focused attention is the most consistent account for the self-awareness effect that we report (Baltazar et al., 2014). Several authors have postulated that heightened attention to the self leads to more accurate awareness of bodily signals (Ainley, Maister, Brokfeld, Farmer, \& Tsakiris, 2013; Ainley, Tajadura-Jiménez, Fotopoulou, \& Tsakiris, 2012). Thus, by triggering the experience of 
oneself as the object of another person's attention, the belief to be watched would enhance self-focused attention and elicit self-awareness.

While the Observed condition did not elicit higher arousal than the other context conditions, there was a main effect of Group on the participant's SCR magnitude. The participants of the deceived group showed higher arousal than the participants of the not-deceived group. This is in line with previous evidence that the real presence of an individual increases arousal (Hietanen, Leppänen, Peltola, Linna-Aho, \& Ruuhiala, 2008; Pönkänen et al., 2011; Zajonc, 1965) and - in return - it strengthens the view that the individuals of the deceived group truly believed to be in live interaction with another individual. Considering that the not-deceived group included participants who had already experienced laboratory setups involving deception procedure ${ }^{1}$ - in contrast to the deceived participants - it is possible that the novelty of experimental condition may also at least in part account for the higher objective arousal (SCR amplitude) in the deceived than the not-deceived group. Indeed, novelty has been shown to increase autonomic responses (Bradley, Lang, \& Cuthbert, 1993). Importantly however, it seems unlikely that the effect of Group on SCR could explain our main result, because this result consisted in an interaction between the Context condition and the Group. Indeed,

\footnotetext{
${ }^{1}$ Our participants were recruited through a list of volunteers made available to Parisian laboratories in cognitive research. Some of these volunteers have already participated in studies where they were led to believe to be observed through a video camera or to be in interaction with other persons while this was not true as revealed after hand. This is why we conducted a debriefing at the end of the experiment to assess the belief of our participants to have been in online connection with another person.
} 
while SCR was greater in the deceived group, it did not differ between Context conditions within the group.

The belief in deception procedure has been shown to be a key factor in the studies on the impact of other's gaze on perception and cognition (e.g. Teufel et al., 2013; Wiese et al., 2012). However, it may be noted that by introducing this between-subject factor in our analyses, we ended up with groups of limited size (17 in the deceived group and 14 in the not-deceived group). Recently, sample size in neuroscience has become a growing concern as it may cause problems with replicability (Ioannidis, 2015; Open Science Collaboration, 2015). Our study is in the power range of most of neuroscience studies. Yet this range has been suggested to be too modest to ensure reliable statistical results (Button et al., 2013). To increase the reliability of low-powered studies, some solutions have been suggested such as pre-specification of the design and the analysis plan, disclosure of all measures, conditions, outcomes, and data exclusions, and high prestudy odds of observing the investigated effects (Button et al., 2013; Ioannidis, Munafò, Fusar-Poli, Nosek, \& David, 2014; Simmons, Nelson, \& Simonsohn, 2012). We followed all these requirements, therefore we are confident in the reliability of our result, even if it is important to keep our sample size limitation in mind.

One may notice that the correlations between participant's SCRs and subjective ratings were overall low. However, considering the literature on interoceptive accuracy, this result was expected. Studies in this area showed that humans are not really accurate in perceiving their bodily responses (Ainley et al., 2013, 2012; Ainley \& Tsakiris, 2013; Garfinkel et al., 2015). This is also in line with a study that evaluated interoceptive accuracy by asking participants to evaluate their SCR magnitude (Andor, Gerlach, \& Rist, 
2008). This study revealed that control participants did not perform this task well, since they tended to negate the perception of their arousal in $64 \%$ of the trials.

Our results extend previous finding on direct gaze perception. We recently demonstrated that bodily self-awareness is enhanced when one perceives direct gaze (Baltazar et al., 2014). Here, we further demonstrate that the belief to be watched by another individual influences bodily self-awareness in a similar way. Yet, it may be noted that in the present study, the belief to be in online connection with the other person was required to observe the self-awareness effect of the belief to be watched, while the effect of direct gaze on self-awareness was previously demonstrated with photograph stimuli. How to reconcile these apparently discrepant findings? We propose that the belief to be the target of someone else's attention is intimately embedded in the perception of direct gaze (see Conty, George, \& Hietanen, 2016). A picture of direct gaze may thus automatically activate the belief to be watched. However, the belief to be watched can be experimentally dissociated from gaze stimuli. This may be the case for example when photograph stimuli are directly compared with the presence of a real person (Hietanen et al., 2008; Pönkänen et al., 2011), because the artificial nature of the photograph stimuli is then enforced in contrast with the real person stimuli. It seems also to be the case when the other's eyes are not visible and participants are led to believe that this other person can see or not, as in Teufel's studies (Teufel et al., 2009; Teufel, Fletcher, \& Davis, 2010) and in the present study. In these cases, it seems that the belief to be in live, on line interaction with the interlocutor is a pre-requisite for attributing the mental state "seeing" to this interlocutor (Teufel et al., 2013). The automatic or by-default mental state attribution to face pictures and its disruption by experimental manipulation was also nicely demonstrated by Wiese et al. (2012). In this latter study, the attention orienting effect induced by the gaze movement of a face 
picture was reduced when the participants were instructed that the gaze movements of the picture were controlled by a computer, as compared to when the participants were instructed that the gaze movements reflected in live the intentional gaze movements of an experimenter. Moreover, another recent study showed that the specific autonomic and brain responses to live direct gaze as compared to live averted gaze were observed only when the participants believed that the stimulus person seated on the other side of an electronic glass shutter was able to see them through the shutter (Myllyneva \& Hietanen, 2015b). In sum, all these results provide converging evidence that mental state attribution is key in the psychological effects that are associated with gaze perception. Thus, the effect of direct gaze on self-awareness is tightly linked to the social significance of direct gaze as signalling that "someone else's attention is directed at myself" (Conty et al., 2016; Hamilton, 2016).

Senju and Johnson (2009) have proposed a fast-track modulator model of direct gaze effects in which "perceived eye contact is initially detected by a subcortical route, which then modulates the activation of the social brain as it processes the accompanying detailed sensory information". Our results further suggest that direct gaze perception is tightly associated with some basic mentalizing processes - namely, attributing the mental state of "seeing", thus arguing for a key role of cortical processes or subcorticalcortical process interactions in at least some effects of direct gaze, such as the effect of direct gaze on self-awareness.

The eyes were not visible in our context stimuli, but these stimuli consisted in front view videoed faces. Therefore, we cannot exclude some implication of the low visual properties of direct gaze in the self-awareness effect reported here. Indeed, one can wonder whether a face with sunglasses is really gaze-free, or if it automatically activates 
the mental representation of the eyes and gaze of the seen face. What is ultimately constitutive of gaze (physical properties and/or mental representations)? It would be interesting to investigate whether the "belief to be watched" per se (i.e. when the interlocutor is not visible at all) might be sufficient to influence bodily self-awareness (see Myllyneva \& Hietanen, 2015a). It would also be interesting to compare gaze with other interpersonal contact cues (e.g. touch or calling someone's name) in order to test if there is anything special in the self-awareness effect elicited by gaze contact and to understand fully the effects of interpersonal contact on self-representation and social interaction. Finally, we did not include emotional valence in our analysis, because our design (with only 8 pictures of positive and negative valence respectively) was not adapted for this. Considering available evidence for interactions between of emotional valence and social context effects (e.g. Kraut, 1982; Lee \& Wagner, 2002), it would be interesting in the future to elaborate new protocols in order to address this question.

\section{Conclusion}

Our results showed that the belief to be watched by another person was associated with an increase in bodily self-awareness, just as the perception of a direct gaze was (Baltazar et al., 2014). Taken together with other studies (Hietanen et al., 2008; Myllyneva \& Hietanen, 2015b; Pönkänen et al., 2011; Teufel et al., 2013), they suggest that the belief to be watched by another person is a basic form of mentalizing embedded in direct gaze perception.

Acknowledgements: This work was supported by the European Research Council (advanced grant, $\mathrm{n}^{\circ} 269616$ to LC), by the Agence Nationale de la Recherche (Grant 
numbers ANR-13-JSH2-0001-01 to LC and ANR-12-SAMA-01104 to N.G.) and by the French program "Investissements d'avenir" (Grant numbers ANR-10-IAIHU-06 and ANR-11-INBS- 0006).

Author Contributions: N.H. designed the experiments, collected, analysed, and interpreted the data, and wrote the manuscript. L.C. and N.G. supervised the research project and contributed to the experimental design, data analyses and interpretation, and to the writing of the manuscript. M.B. contributed to the experimental design and to the writing of the manuscript. 


\section{REFERENCES}

Ainley, V., Maister, L., Brokfeld, J., Farmer, H., \& Tsakiris, M. (2013). More of myself: Manipulating interoceptive awareness by heightened attention to bodily and narrative aspects of the self. Consciousness and Cognition, 22(4), 1231-1238. http://doi.org/10.1016/j.concog.2013.08.004

Ainley, V., Tajadura-Jiménez, A., Fotopoulou, A., \& Tsakiris, M. (2012). Looking into myself: changes in interoceptive sensitivity during mirror self-observation. Psychophysiology, 49(11), 1504-1508. http://doi.org/10.1111/j.14698986.2012.01468.x

Ainley, V., \& Tsakiris, M. (2013). Body conscious? Interoceptive awareness, measured by heartbeat perception, is negatively correlated with self-objectification. PLOS ONE, 8(2), e55568. http://doi.org/10.1371/journal.pone.0055568

Andor, T., Gerlach, A. L., \& Rist, F. (2008). Superior perception of phasic physiological arousal and the detrimental consequences of the conviction to be aroused on worrying and metacognitions in GAD. Journal of Abnormal Psychology, 117(1), 193205. http://doi.org/10.1037/0021-843X.117.1.193

Argyle, M. (1975). Bodily communication. Oxford England: International Universities Press.

Auzoult, L. (2013). A French version of the situational self-awareness scale. Revue Européenne de Psychologie Appliquée/European Review of Applied Psychology, 63(1), 41-47. http://doi.org/10.1016/j.erap.2012.08.004

Baltazar, M., Hazem, N., Vilarem, E., Beaucousin, V., Picq, J. L., \& Conty, L. (2014). Eye contact elicits bodily self-awareness in human adults. Cognition, 133(1), 120-127. http://doi.org/10.1016/j.cognition.2014.06.009

Bradley, M. M., Codispoti, M., Cuthbert, B. N., \& Lang, P. J. (2001). Emotion and motivation I: defensive and appetitive reactions in picture processing. Emotion, 1(3), 276-298. http://doi.org/10.1037/1528-3542.1.3.276

Bradley, M. M., Lang, P. J., \& Cuthbert, B. N. (1993). Emotion, novelty, and the startle reflex: Habituation in humans. Behavioral Neuroscience, 107(6), 970-980. http://doi.org/10.1037/0735-7044.107.6.970

Button, K. S., Ioannidis, J. P. A., Mokrysz, C., Nosek, B. A., Flint, J., Robinson, E. S. J., \& Munafò, M. R. (2013). Power failure: why small sample size undermines the reliability of neuroscience. Nature Reviews Neuroscience, 14(5), 365-376. http://doi.org/10.1038/nrn3475

Cameron, 0. G. (2001). Interoception: the inside story--a model for psychosomatic processes. Psychosomatic Medicine, 63(5), 697-710. http://doi.org/00333174/01/6305-0697

Chentsova-Dutton, Y. E., \& Dzokoto, V. (2014). Listen to your heart: the cultural shaping 
of interoceptive awareness and accuracy. Emotion, 14(4), 666-78. http://doi.org/10.1037/a0036193

Conty, L., George, N., \& Hietanen, J. K. (2016). Watching Eyes effects: When others meet the self. Consciousness and Cognition, 45, 184-197. http://doi.org/10.1016/j.concog.2016.08.016

Conty, L., Tijus, C., Hugueville, L., Coelho, E., \& George, N. (2006). Searching for asymmetries in the detection of gaze contact versus averted gaze under different head views: a behavioural study. Spatial Vision, 19(6), 529-545. http://doi.org/10.1163/156856806779194026

Craig, A. D. B. (2008). Interoception and emotion: a neuroanatomical perspective. In M. Lewis, J. M. Haviland-Jones, \& L. F. Barrett (Eds.), Handbook of emotions (3rd ed., pp. 272-288). New York: Guildford Press.

Damasio, A. R., \& Carvalho, G. B. (2013). The nature of feelings: evolutionary and neurobiological origins. Nature Reviews. Neuroscience, 14(2), 143-52. http://doi.org/10.1038/nrn3403

Farb, N., Daubenmier, J., Price, C. J., Gard, T., Kerr, C., Dunn, B. D., ... Mehling, W. E. (2015). Interoception, contemplative practice, and health. Frontiers in Psychology, 6, 763. http://doi.org/10.3389/fpsyg.2015.00763

Fullwood, C., \& Doherty-Sneddon, G. (2006). Effect of gazing at the camera during a video link on recall. Applied Ergonomics, 37(2), 167-175. http://doi.org/10.1016/j.apergo.2005.05.003

Garfinkel, S. N., Seth, A. K., Barrett, A. B., Suzuki, K., \& Critchley, H. D. (2015). Knowing your own heart: Distinguishing interoceptive accuracy from interoceptive $\begin{array}{llll}\text { awareness. } & \text { Biological }\end{array}$ http://doi.org/10.1016/j.biopsycho.2014.11.004

Govern, J. M., \& Marsch, L. A. (2001). Development and validation of the situational selfawareness scale. Consciousness and Cognition, 10(3), 366-378. http://doi.org/10.1006/ccog.2001.0506

Hamilton, A. F. de C. (2016). Gazing at me: the importance of social meaning in understanding direct-gaze cues. Philosophical Transactions of the Royal Society of London. Series B, Biological Sciences, 371(1686), 20150080-. http://doi.org/10.1098/rstb.2015.0080

Helminen, T. M., Kaasinen, S. M., \& Hietanen, J. K. (2011). Eye contact and arousal: The effects of stimulus duration. Biological Psychology, 88(1), 124-30. http://doi.org/10.1016/j.biopsycho.2011.07.002

Hietanen, J. K., Leppänen, J. M., Peltola, M. J., Linna-Aho, K., \& Ruuhiala, H. J. (2008). Seeing direct and averted gaze activates the approach-avoidance motivational brain systems. Neuropsychologia, 46(9)

http://doi.org/10.1016/j.neuropsychologia.2008.02.029 
Howell, D. C. (2012). Statistical Methods for Psychology (8th ed.). Pacific Grove, CA: Wadsworth Publishing.

Ioannidis, J. P. A. (2015). Failure to Replicate: Sound the Alarm. Cerebrum: The Dana Forum on Brain Science, 2015.

Ioannidis, J. P. A., Munafò, M. R., Fusar-Poli, P., Nosek, B. A., \& David, S. P. (2014). Publication and other reporting biases in cognitive sciences: detection, prevalence and prevention. Trends in Cognitive Sciences, 18(5), 235. http://doi.org/10.1016/j.tics.2014.02.010

Jones, E. E. (1990). Interpersonal perception. New York: W.H. Freeman.

Kraut, R. E. (1982). Social presence, facial feedback, and emotion. Journal of Personality and Social Psychology, 42(5), 853-863. http://doi.org/10.1037/00223514.42.5.853

Lang, P. J., Bradley, M. M., \& Cuthbert, B. N. (2008). International affective picture system (IAPS): Affective ratings of pictures and instruction manual. Technical Report A-8. University of Florida, Gainesville, FL. http://doi.org/10.1016/j.epsr.2006.03.016

Lang, P. J., Greenwald, M. K., Bradley, M. M., \& Hamm, A. O. (1993). Looking at pictures: affective, facial, visceral, and behavioral reactions. Psychophysiology, 30(3), 261273. http://doi.org/10.1111/j.1469-8986.1993.tb03352.x

Lee, V., \& Wagner, H. (2002). The Effect of Social Presence on the Facial and Verbal Expression of Emotion and the Interrelationships Among Emotion Components. Journal of Nonverbal Behavior, 26(1), 3-25. http://doi.org/10.1023/A:1014479919684

Mason, M. F., Hood, B. M., \& Macrae, C. N. (2004). Look into my eyes: gaze direction and person memory. Memory, 12(5), 637-643. http://doi.org/10.1080/09658210344000152

Mendes, W. (2009). Assessing autonomic nervous system activity. In Methods in social neuroscience (pp. 118-147).

Myllyneva, A., \& Hietanen, J. K. (2015a). The dual nature of eye contact: to see and to be seen. Social Cognitive and Affective Neuroscience. http://doi.org/10.1093/scan/nsv075

Myllyneva, A., \& Hietanen, J. K. (2015b). There is more to eye contact than meets the eye. Cognition, 134, 100-109. http://doi.org/10.1016/j.cognition.2014.09.011

Napieralski, L. P., Brooks, C. I., \& Droney, J. M. (1995). The effect of duration of eye contact on American college students' attributions of state, trait, and test anxiety. The Journal of Social Psychology, 135(3), 273-280. http://doi.org/10.1080/00224545.1995.9713957

Nettle, D., Harper, Z., Kidson, A., Stone, R., Penton-Voak, I. S., \& Bateson, M. (2013). The watching eyes effect in the Dictator Game: it's not how much you give, it's being 
seen to give something. Evolution and Human Behavior, 34(1), 35-40. http://doi.org/10.1016/j.evolhumbehav.2012.08.004

Nichols, K. A., \& Champness, B. G. (1971). Eye gaze and the GSR. Journal of Experimental Social Psychology, 7(6), 623-626. http://doi.org/10.1016/0022-1031(71)90024-2

Open Science Collaboration. (2015). Estimating the reproducibility of psychological science. Science. Retrieved from http://science.sciencemag.org/content/349/6251/aac4716.short

Pönkänen, L. M., Peltola, M. J., \& Hietanen, J. K. (2011). The observer observed: Frontal EEG asymmetry and autonomic responses differentiate between another person's direct and averted gaze when the face is seen live. International Journal of Psychophysiology, 82(2), 180-187. http://doi.org/10.1016/j.ijpsycho.2011.08.006

Reddy, V. (2003). On being the object of attention: Implications for self-other consciousness. Trends in Cognitive Sciences, 7(9), 397-402. http://doi.org/10.1016/S1364-6613(03)00191-8

Senju, A., \& Hasegawa, T. (2005). Direct gaze captures visuospatial attention. Visual Cognition. http://doi.org/10.1080/13506280444000157

Senju, A., Hasegawa, T., \& Tojo, Y. (2005). Does perceived direct gaze boost detection in adults and children with and without autism? The stare-in-the-crowd effect revisited. Visual Cognition, 12(8), 1474-1496. http://doi.org/10.1080/13506280444000797

Senju, A., \& Johnson, M. H. (2009). The eye contact effect: mechanisms and development. Trends in Cognitive Sciences, 13(3), 127-134. http://doi.org/10.1016/j.tics.2008.11.009

Silvia, P. J., \& Gendolla, G. H. E. (2001). On introspection and self-perception: Does selffocused attention enable accurate self-knowledge? Review of General Psychology, 5, 241-269. http://doi.org/10.1037/1089-2680.5.3.241

Simmons, J. P., Nelson, L. D., \& Simonsohn, U. (2012). A 21 Word Solution. SSRN Electronic Journal. http://doi.org/10.2139/ssrn.2160588

Teufel, C., Alexis, D. M., Clayton, N. S., \& Davis, G. (2010). Mental-state attribution drives rapid, reflexive gaze following. Attention, Perception \& Psychophysics, 72(3), 695705. http://doi.org/10.3758/APP.72.3.695

Teufel, C., Alexis, D. M., Todd, H., Lawrance-Owen, A. J., Clayton, N. S., \& Davis, G. (2009). Social Cognition Modulates the Sensory Coding of Observed Gaze Direction. Current Biology, 19(15), 1274-1277. http://doi.org/10.1016/j.cub.2009.05.069

Teufel, C., Fletcher, P. C., \& Davis, G. (2010). Seeing other minds: Attributed mental states influence perception. Trends in Cognitive Sciences, 14(8), 376-382. http://doi.org/10.1016/j.tics.2010.05.005

Teufel, C., von dem Hagen, E., Plaisted-Grant, K. C., Edmonds, J. J., Ayorinde, J. O., Fletcher, 
P. C., \& Davis, G. (2013). What is social about social perception research? Frontiers in Integrative Neuroscience, 6, 128. http://doi.org/10.3389/fnint.2012.00128

Vuilleumier, P., George, N., Lister, V., Armony, J. L., \& Driver, J. (2005). Effects of perceived mutual gaze and gender on face processing and recognition memory. Visual Cognition, 12(1), 85-101. http://doi.org/10.1080/13506280444000120

Wang, Y., Newport, R., \& Hamilton, A. F. de C. (2011). Eye contact enhances mimicry of intransitive hand movements. Biology Letters, 7(1), 7-10. http://doi.org/10.1098/rsbl.2010.0279

Wiese, E., Wykowska, A., Zwickel, J., \& Müller, H. J. (2012). I See What You Mean: How Attentional Selection Is Shaped by Ascribing Intentions to Others. PLoS ONE, 7(9), 1-7. http://doi.org/10.1371/journal.pone.0045391

Wykowska, A., Wiese, E., Prosser, A., \& Müller, H. J. (2014). Beliefs about the minds of others influence how we process sensory information. PloS One, 9(4), e94339. http://doi.org/10.1371/journal.pone.0094339

Zajonc, R. B. (1965). Social Facilitation. Science, 149(3681), 269-274. http://doi.org/10.1126/science.149.3681.269 


\section{FIGURE CAPTIONS}

Figure 1. Experimental design: time course of an experimental trial. The emotional picture depicted in the figure is in public domain (from http://www.publicdomainpictures.net/] and not from the used IAPS stimulus set.

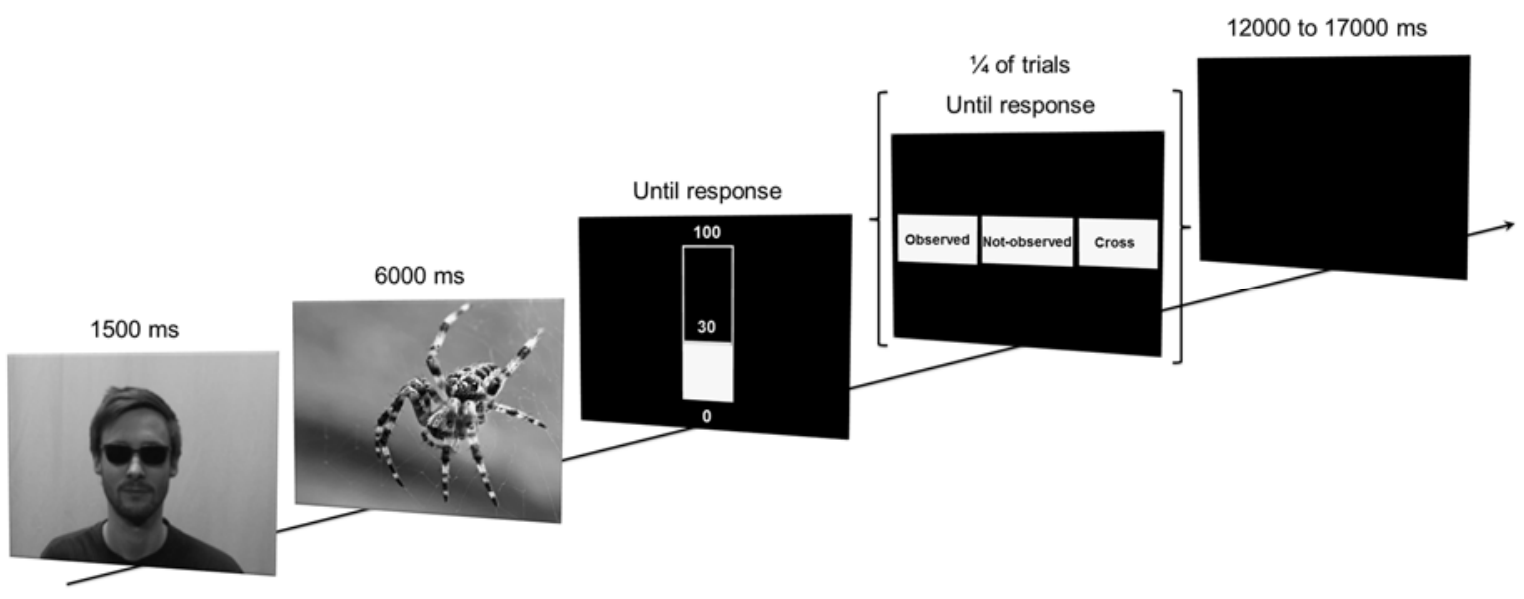


Figure 2. Correlations between skin conductance responses (SCR) magnitude and subjective ratings. (a) The mean correlation between the participants' SCR and ratings is indicated in Fisher's $\mathrm{z}$ scores for each context condition (Observed/Notobserved/Cross) and for each group of participants (Deceived/Not-deceived). Significant differences are indicated with asterisks $(*: p<.05)$. Vertical bars represent standard errors of the means. (b) Individual data: The correlation between SCRs and ratings obtained for each participant in each condition (Observed/Not-observed/Cross) is indicated in Fisher's z scores. Black and grey dots depict the Deceived and Notdeceived participants respectively.

a.

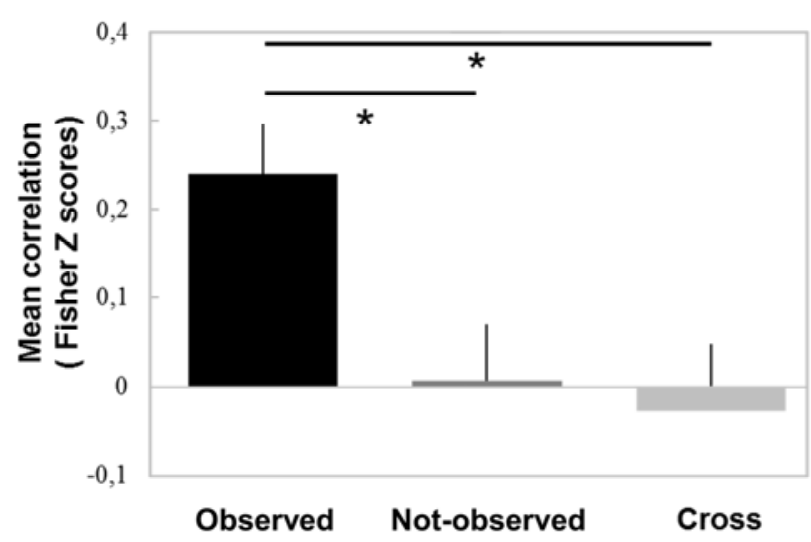

Not-deceived

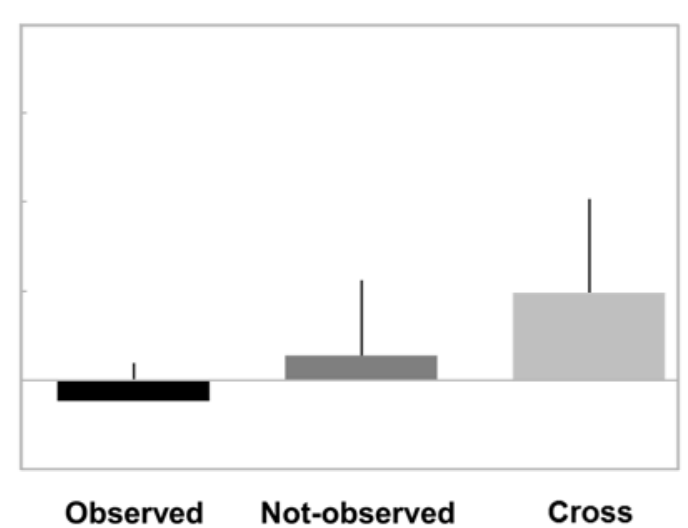

b.

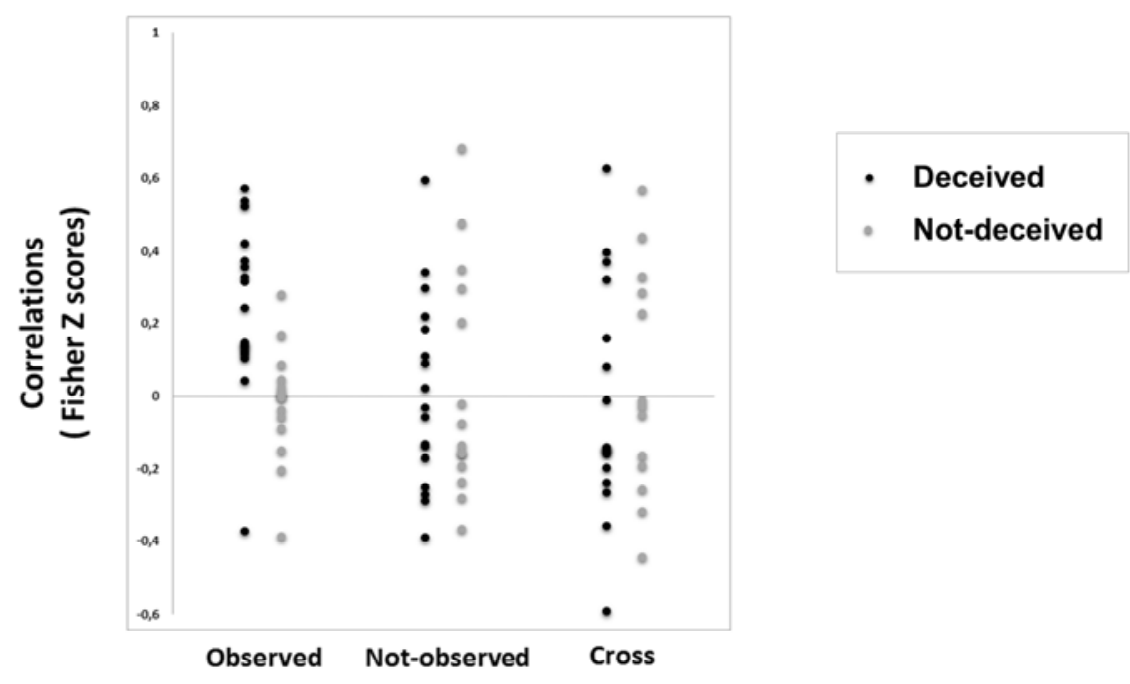


Table 1. Effects of context on subjective ratings and physiological activity. All values are expressed as mean \pm standard error of the mean. SCRs are expressed in $\log (\mu S+1)$

\begin{tabular}{lllll}
\hline & & Observed & Not-observed & Cross \\
\hline Deceived & SCRs & $0.051 \pm .016$ & $0.053 \pm .015$ & $0.058 \pm .016$ \\
$(\mathbf{N = 1 7 )}$ & Ratings & $42.4 \pm 2.9$ & $42.8 \pm 3.3$ & $44.5 \pm 2.5$ \\
\hline Not-deceived & SCRs & $0.022 \pm .006$ & $0.024 \pm .008$ & $0.021 \pm .005$ \\
$(\mathbf{N = 1 4 )}$ & Ratings & $36.0 \pm 4.3$ & $36.5 \pm 4.8$ & $34.2 \pm 4.3$
\end{tabular}

